\title{
PERANCANGAN DAN REALISASI PURWARUPA SISTEM MONITORING AREA PARKIR MOBIL DENGAN MENGGUNAKAN ULTRASONIK DAN LIGHT DEPENDENT RESISTOR
}

\author{
Ivany Sarief ${ }^{1)}$, Wulandari Pancadasa Merdeka Putri ${ }^{2}$, BambangSugiarto ${ }^{3)}$ \\ Universitas Sangga Buana YPKP Bandung ${ }^{1,2)}$ \\ Pusat Penelitian Informatika - Lembaga Ilmu Pengetahuan Indonesia ${ }^{3)}$ \\ ivansarief@gmail.com ${ }^{1)}$,wulanpanca12@ gmail.com ${ }^{2)}$, bambang@informatika.lipi.go.id ${ }^{3)}$
}

\begin{abstract}
ABSTRAK
Kebanyakan fasilitas parkir yang digunakan saat ini tidak memberikan informasi yang menandakan bahwa slot parkir yang tersedia sudah penuh. Hal ini membuat pengguna jasa parkir terutama pengendara kendaraan roda 4 (mobil) membutuhkan waktu lebih dari 10 menit untuk menemukan tempat parkir yang tersedia. Berdasarkan hal tersebut, dirancang sebuah purwarupa sistem untuk mempermudah pengendara mobil yang hendak menggunakan jasa parkir dengan cara membuka dan menutup palang pintu parkir secara otomatis, serta memberikan informasi slot parkir yang masih tersedia. Pada sistem ini, proses pengambilan data dilakukan oleh mikrokontroler yang bertindak sebagai komponen kendali utama. Pengujian dilakukan melalui sebuah purwarupa miniatur perparkiran. Purwarupa menggunakan sensor ultrasonik untuk mengaktifkan palang pintu, motor servo sebagai penggerak palang pintu masuk dan palang pintu keluar, dan sensor Light Dependent Resistor (LDR) mendeteksi keberadaan mobil pada slot parkir. LDR ditempatkan dilantai pada setiap bidang slot parkir. Ketika ada benda diatas LDR maka cahaya akan tertutup sehingga LDR mendeteksi benda dan mengirim data pada mikrokontroler, yang akan mendefinisikan bahwa tempat tadi sudah diisi kendaraan dan menampilkan keluaran di Personal Computer (PC) bahwa slot parkir sudah penuh atau belum. Hasil pengujian sistem perparkiran dapat menampilkan kondisi masing-masing area parkir di PC dengan menggunakan aplikasi visual basic sebagai penampilnya. Portal masuk tidak dapat terbuka jika semua slot parkir telah terisi dan buzzer akan berbunyi sebagai tanda alarm.
\end{abstract}

Kata kunci: slot parkir, mikrokontroler ,ultrasonik, LDR, buzzer

\section{PENDAHULUAN}

Seiring perkembangan jaman, penggunaan kendaraan pribadi sebagai alat transportasi sudah menjadi hal yang umum. Hal ini berdampak pada semakin banyaknya lahanlahan parkir yang disediakan oleh tempattempat umum. Akan tetapi hal ini tidak disertai dengan peningkatan kualitas dan kenyamanan tempat parkir tersebut, terutama untuk pengendara mobil.

Para pengguna mobil pribadi yang hendak parkir, kurang mendapat informasi mengenai keadaan area parkir serta lokasi ketersediaan slot area parkir yang kosong. Akibat dari kurangnya informasi yang di dapat, seringkali para pengguna mobil perlu memakan waktu yang cukup lama untuk sekedar menemukan slot area parkir yang kosong. Bahkan tidak jarang pada akhirnya pengguna mobil tidak mendapat tempat parkir sama sekali.

Untuk meningkatkan ketertiban dan kenyamanan area parkir, dikembangkan suatu sistem parkir mobil dengan menggunakan sensor pendeteksi berbasiskan Mikrokontroler dengan aplikasi monitoring area parkir. Dengan sistem tersebut, diharapkan permasalahan akan kurangnya informasi yang didapat oleh pengendara mobil mengenai ketersediaan lahan parkir serta lokasi tempat parkir yang masih kosong dapat teratasi. 


\subsection{Mikrokontroler AVR ATMega328}

Salah satu keluarga AVR 8 bit ini memiliki ukuran fisik lebih kecil dibandingkan dengan beberapa mikrokontroler lainnya. Namun untuk segi memori dan periperal lainnya,
ATMega328 tidak kalah dengan yang lainnya karena ukuran memori dan periperalnya relatif sama dengan ATMega85

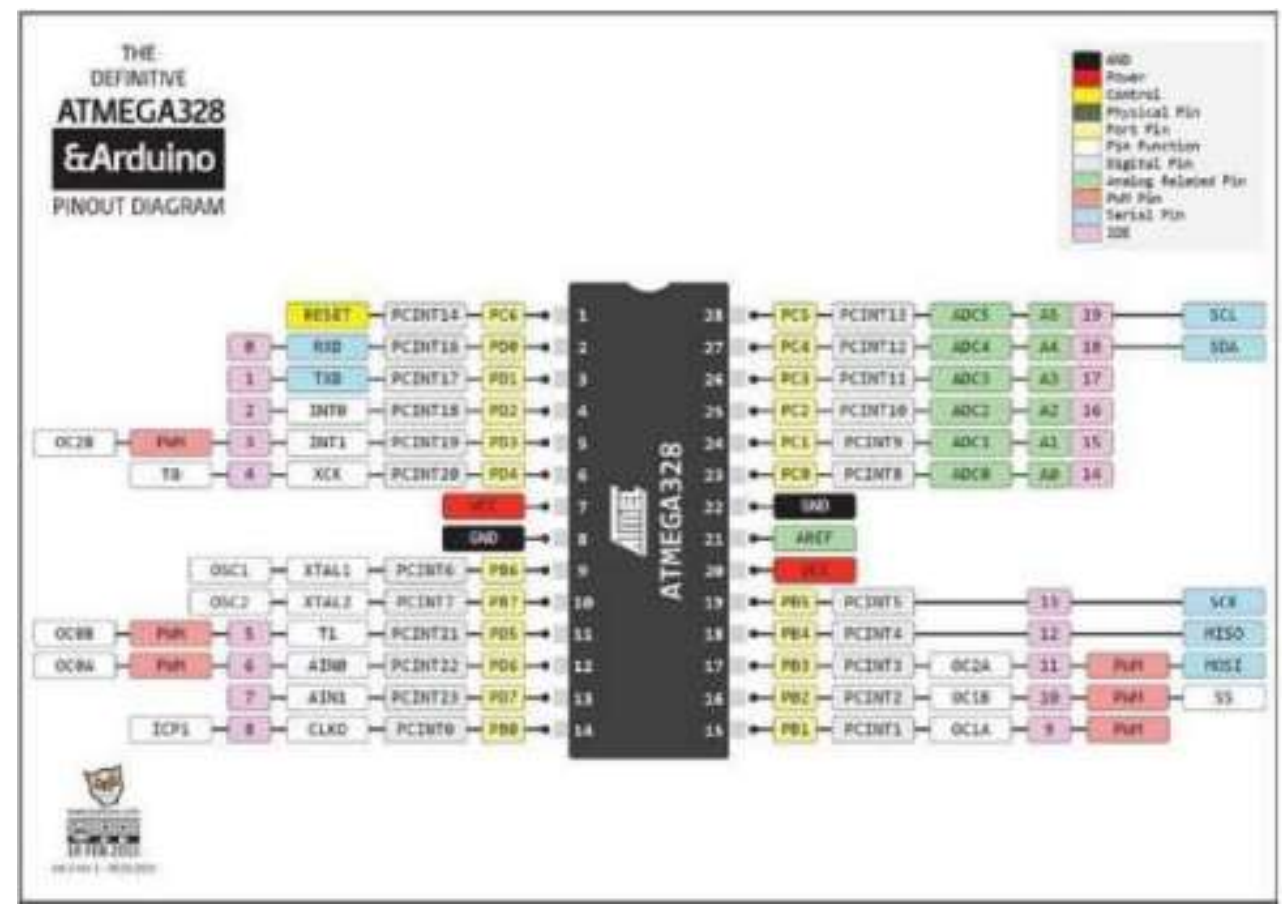

Gambar 1. Pin Mikrokontroler ATMega328

\subsection{Arduino Uno}

Arduino Uno adalah board mikrokontroler berbasis ATMega328. Memiliki 14 pin Input/Output Digital dimana 6 pin tersebut dapat digunakan sebagai output PWM (Pulse Widht Modulation), 5 pin Input / Output Analog dimana 2 pin tersebut digunakan SCL dan SDA, Osilator Kristal 16 MHz, Koneksi USB, Jack Power, ICSP Header dan Tombol Reset. Untuk mendukung mikrokontroler agar dapat digunakan, cukup dengan menghubungkan board Arduino Uno ke komputer dengan menggunakan kabel USB, power supply atau baterai untuk menjalankannya.

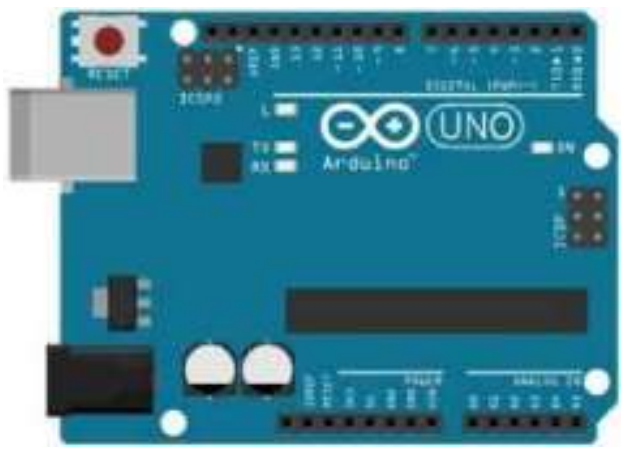

Gambar 2. Board Arduino Uno

\subsection{Sensor Ultrasonik HC-SR04}

Fungsi dari sensor adalah sebagai pengirim, penerima, dan pengontrol gelombang ultrasonik. Sensor ini bisa digunakan untuk mengukur jarak benda dari $2 \mathrm{~cm}-4 \mathrm{~m}$ dengan akurasi $3 \mathrm{~mm}$. alat ini memiliki 4 pin : pin Vcc, Gnd, Trigger dan Echo. Pin Vcc untuk listrik positif (sumber tegangan) dan Gnd untuk ground nya. Pin Trigger untuk trigger 
keluarnya sinyal dan sensor dan pin Echo untuk menangkap sinyal pantul dari benda.

Cara menggunakannya yaitu ketika kita memberikan tegangan positif pada pin Trigger selama $10 \mu \mathrm{S}$, maka sensor akan mengirimkan 8 step sinyal ultrasonik dengan frekuensi $40 \mathrm{kHz}$. Selanjutnya, sinyal akan diterima pada pin Echo. Untuk mengukur jarak benda yang memantulkan sinyal tersebut, digunakan selisih waktu ketika mengirim dan menerima sinyal.

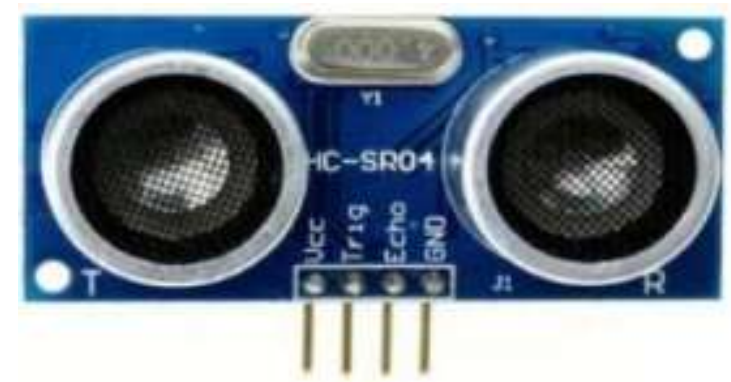

Gambar 3. Sensor Ultrasonik HC-SR04

\subsection{Sensor LDR}

Merupakan salah satu jenis sensor cahaya, yang bisa digunakan untuk membangun sistem yang berkaitan dengan cahaya seperti jemuran otomatis, tracking arah sumber cahaya matahari, atau sebagai pengatur intensitas cahaya lampu untuk tanaman didalam ruangan dan banyak lagi lainnya. Di pasaran ada LDR yang berukuran $4 \mathrm{~mm}$ dan $11 \mathrm{~mm}$. LDR disebut juga sebagai photoresistor sebab alat ini akan memiliki resistansi yang akan berubah seiring dengan perubahan intensitas cahaya yang mengenainya. Dalam kondisi gelap, resistansi LDR bisa mencapai $10 \mathrm{M} \Omega$, tapi dalam kondisi terang resistansi LDR turun hingga $1 \mathrm{~K} \Omega$ bahkan bisa lebih kecil lagi. Sifat inilah yang membuat LDR bisa dimanfaatkan sebagai sensor cahaya.

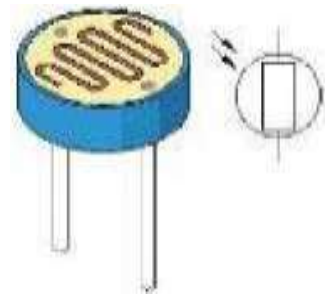

Gambar 4. LDR

\subsection{Motor Servo}

Motor servo adalah sebuah motor dengan sistem closed feedback dimana posisi dari motor akan diinformasikan kembali ke rangkaian kontrol yang ada di dalam motor servo. Motor ini terdiri dari sebuah motor, serangkaian gear, potensiometer dan rangkaian kontrol. Potensiometer berfungsi untuk menentukan batas sudut dari putaran servo. Sedangkan sudut dari sumbu motor servo diatur berdasarkan lebar pulsa yang dikirim melalui kaki sinyal dari kabel motor.

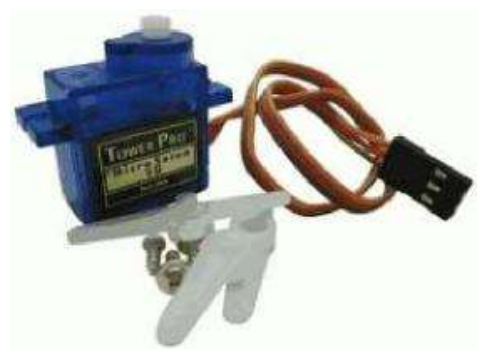

Gambar 5. Motor Servo

Motor servo memiliki:

1. 3 jalur kabel : power, gnd dan kontrol.

2. Sinyal kontrol mengendalikan posisi.

3. Operasional dari motor servo dikendalikan oleh sebuah pulsa selebar $\pm 20 \mathrm{~ms}$.

4. Kontruksi didalamnya meliputi internal gear, potensiometer dan feedback control.

\subsection{Buzzer}

Buzzer adalah komponen elektronika yang dapat mengubah sinyal listrik menjadi getaran suara. Jenis buzzer yang sering ditemukan dan digunakan adalah buzzer berjenis Piezoelectic, hal ini dikarenakan kelebihan Piezoelectic memiliki berbagai kelebihan seperti lebih murah, relatif lebih ringan dan lebih mudah dalam menggabungkan ke rangkaian elektronika lainnya. Buzzer yang termasuk keluarga transduser ini juga sering disebut Beeper 


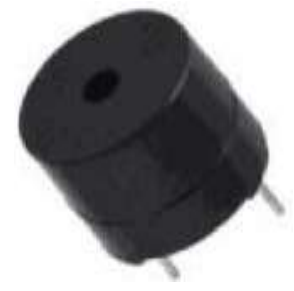

Gambar 6. Buzzer

\subsection{Visual Basic 6.0}

Microsoft Visual Basic (VB) 6.0 adalah salah satu aplikasi untuk membuat sistem informasi database. VB 6.0 merupakan versi terbaru dari VB 1 sampai 5. Walau agak tertinggal, tapi software ini masih digunakan untuk diimplementasikan dalam pembuatan sistem database. VB 6.0 ini pun berkembang menjadi Visual Studio, VB 2008 sampai Visual basic.net. VB 6.0 ini sering juga di gunakan dalam aplikasi perhitungan gaji, penjualan barang dan lain-lain. VB 6.0 mendukung Windows operating system dan untuk basis datanya, digunakan Microsoft Access, SQL Server dan Oracle.

\section{PERANCANGAN SISTEM}

Pada dasarnya sistem ini merupakan penyampaian informasi slot parkir yang kosong dengan menggunakan mikrokontroler sebagai pemrosesan setiap datanya, dimana informasi yang dibutuhkan dapat disampaikan melalui penerimaan data (mobil) yang memasuki area parkir melalui tampilkan di PC dengan menggunakan aplikasi visual basic. Data yang masuk akan diolah sehingga pada PC akan ditampilkan slot area parkir saat kosong maupun terisi. Data tersebut akan ditampilkan secara terus-menerus pada PC selama alat tersebut terhubung dengan daya listrik.

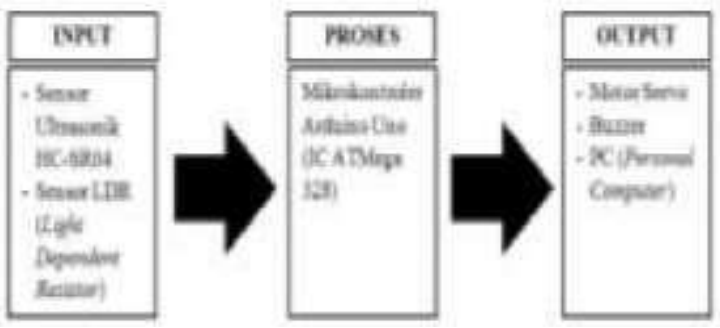

Gambar 7. Blok Diagram Sistem

\subsection{Perancangan Hardware}

Pengujian ini dilakukan dengan menggunakan purwarupa yang dirancang menyerupai lahan parkir pada umumnya, yang memiliki palang pintu dan beberapa slot parkir. Purwarupa yang dirancang memiliki dua buah palang pintu yang jaraknya berbeda dan empat buah slot parkir.

Purwarupa dengan $35 \mathrm{~cm} \times 45 \mathrm{~cm}$ dibagi menjadi 4 bagian yaitu bagian pintu masuk, pintu keluar, bagian kontrol dan bagian slot parkir. Setiap bagian memiliki komponen yang berperan penting untuk mendukung sistem yang telah dirancang. Bagian pintu masuk memiliki panjang $9 \mathrm{~cm}$, bagian slot parkir memiliki panjang $35 \mathrm{~cm}$, bagian kontrol memiliki panjang $17 \mathrm{~cm} \times 16 \mathrm{~cm}$ dan bagian pintu keluar memiliki panjang $9 \mathrm{~cm}$. Ukuran satu slot parkir adalah $7.5 \mathrm{~cm} \mathrm{x} 12 \mathrm{~cm}$.

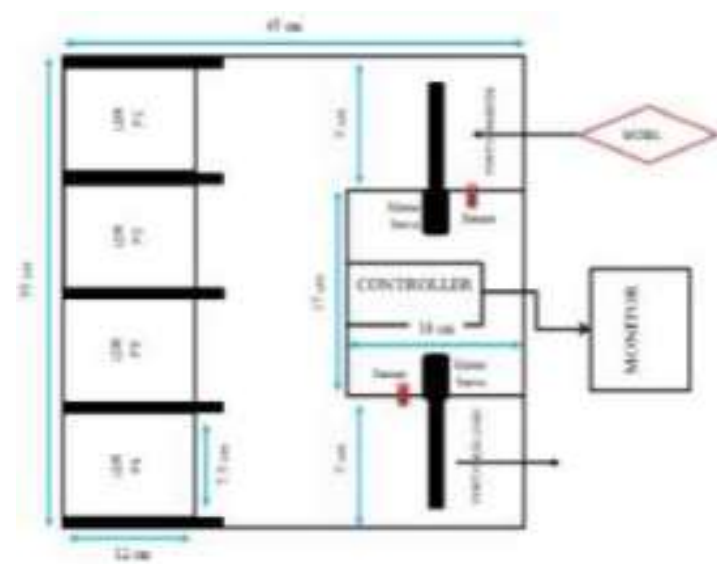

Gambar 8. Layout Purwarupa

\subsection{Perancangan Software}

\subsubsection{Program Arduino IDE}

Program yang akan dimasukan pada board Arduino Uno ditulis pada jendela kosong berwarna putih pada Arduino IDE dengan nama sketch. Sketch dapat disimpan dengan file berekstensi ino atau kita dapat langsung mengupload program yang telah kita buat melalui komunikasi USB yang dihubungkan pada board Arduino Uno. Sebelum meng-upload program sketch, pastikan sudah terhubung jenis board dan port serial yang akan digunakan ketika akan meng-upload sketch. Akan terlihat pada 
sudut kanan bawah yaitu jenis board yang digunakan dan juga port COM yang terhubung.

\subsubsection{Program Visual Basic}

Form aplikasi VB digunakan sebagai tampilan monitoring ketersediaan slot pada area parkir. Dalam pembuatan form aplikasi monitoring ketersediaan slot pada area parkir, komponen VB yang digunakan antara lain :

\section{a. Label}

Untuk memberi nama atau sebagai penampil keterangan pada form aplikasi.

\section{b. Button}

Atau bisa disebut dengan tombol berfungsi untuk mengeksekusi perintah tertentu seperti OK, exit, connect dan lainlain. Dalam pembuatan form aplikasi ini hanya menggunakan 1 button yaitu button connect, yang berfungsi sebagai tombol OK ketika Com Port telah dipilih maka Arduino dan VB telah terhubung.

c. Combo Box

Berfungsi untuk menampilkan item dalam bentuk teks box, kotak daftar atau daftar drop-down. Dalam form ini memakai 2 combo box yaitu untuk memilih com port dan memilih com baudrate yang dibutuhkan.

\section{d. Timer}

Berfungsi untuk mengeksekusi waktu kejadian pada rutin program termasuk interval (selang waktu), mencetak (printing), dan lain-lain.

e. Comm Control berfungsi untuk menghubungkan VB dengan Arduino melalui komunikasi serial. Sehingga data yang diterima oleh arduino dapat terbaca juga oleh VB.

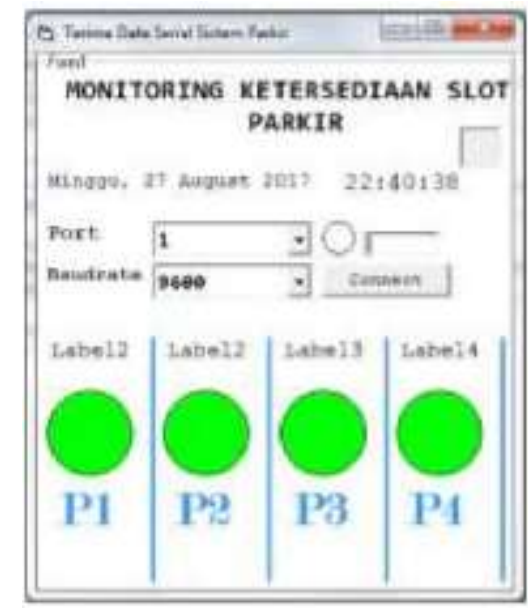

Gambar 10. form monitoring area parker

\section{HASIL DAN PEMBAHASAN}

Dalam pengujian, sistem dibagi menjadi dua modul. Pertama yang berada pada sisi mikrokontroler oleh arduino uno yang berfungsi sebagai pemancar dan penerima gelombang ultrasonik, pendeteksi cahaya pada sensor LDR, penggerak motor servo dan mengirimkan hasil tersebut melalui komunikasi USB. Sedangkan modul kedua yaitu sisi PC melalui komunikasi USB sebagai penampil hasil monitoring dalam aplikasi VB.Pengujian sistem secara keseluruhan dilakukan pada sebuah purwarupa berupa area lahan parkir dengan menguji cobakan kendaraan yang akan masuk dan keluar area parkir.

\subsection{Pengujian Hardware}

Dilakukan 10 kali percobaan pada purwarupa, untuk memperoleh sampel data pergerakan palang pintu saat mobil masuk dan keluar dengan cara mengatur jarak antara mobil dengan sensor ultrasonik mulai dari $0 \mathrm{~cm}$ sampai $10 \mathrm{~cm}$.

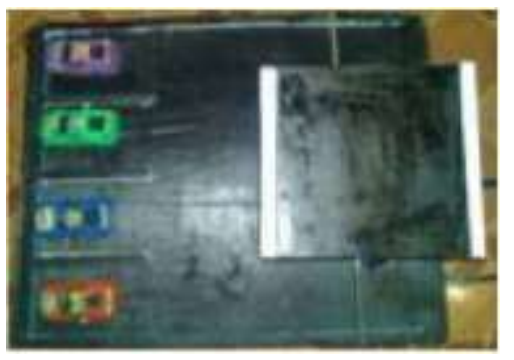

Gambar 11. Prototipe Tampak Atas 


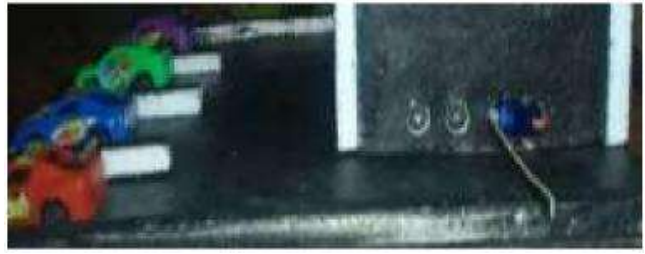

Gambar 12. Prototipe Tampak Samping

Tabel 1:Hasil Uji Coba Pada Pintu Masuk

\begin{tabular}{|c|c|c|}
\hline Uji & $\begin{array}{c}\text { Jarak mobil dengan } \\
\text { sensor }\end{array}$ & Palang pintu \\
\hline 1 & $9 \mathrm{~cm}$ & Tidak Bergerak \\
\hline 2 & $8 \mathrm{~cm}$ & Tidak Bergerak \\
\hline 3 & $7 \mathrm{~cm}$ & Tidak Bergerak \\
\hline 4 & $6 \mathrm{~cm}$ & Tidak Bergerak \\
\hline 5 & $5 \mathrm{~cm}$ & Bergerak \\
\hline 6 & $4 \mathrm{~cm}$ & Bergerak \\
\hline 7 & $3 \mathrm{~cm}$ & Bergerak \\
\hline 8 & $2 \mathrm{~cm}$ & Bergerak \\
\hline 9 & $1 \mathrm{~cm}$ & Bergerak \\
\hline 10 & $0 \mathrm{~cm}$ & Bergerak \\
\hline
\end{tabular}

Tabel 2:Hasil Uji Coba Pada Pintu Keluar

\begin{tabular}{|c|c|c|}
\hline Uji & $\begin{array}{c}\text { Jarak mobil dengan } \\
\text { sensor }\end{array}$ & Palang pintu \\
\hline 1 & $9 \mathrm{~cm}$ & Tidak Bergerak \\
\hline 2 & $8 \mathrm{~cm}$ & Tidak Bergerak \\
\hline 3 & $7 \mathrm{~cm}$ & Tidak Bergerak \\
\hline 4 & $6 \mathrm{~cm}$ & Tidak Bergerak \\
\hline 5 & $5 \mathrm{~cm}$ & Bergerak \\
\hline 6 & $4 \mathrm{~cm}$ & Bergerak \\
\hline 7 & $3 \mathrm{~cm}$ & Bergerak \\
\hline 8 & $2 \mathrm{~cm}$ & Bergerak \\
\hline 9 & $1 \mathrm{~cm}$ & Bergerak \\
\hline 10 & $0 \mathrm{~cm}$ & Bergerak \\
\hline
\end{tabular}

Selain itu dilakukan 16 kali percobaan pada slot area parkir berdasarkan pergerakan mobil (masuk dan keluar) sesuai dengan ketersediaan slot parkir pada purwarupa yang berjumlah 4 slot.

Tabel 3:Hasil Uji Coba Pada Slot Area Parkir

\begin{tabular}{|c|c|c|c|c|c|c|c|c|}
\hline Uji & LDR & Slot P1 & LDR2 & Slot P2 & LDR 3 & Slot P3 & LDR 4 & Slot P4 \\
& 1 & & & & & & \\
\hline 1 & A & Kosong & b & Kosong & c & Kosong & d & Kosong \\
\hline 2 & A & Kosong & b & Kosong & c & Kosong & D & Terisi \\
\hline 3 & A & Kosong & b & Kosong & C & Terisi & d & Kosong \\
\hline 4 & A & Kosong & b & Kosong & C & Terisi & D & Terisi \\
\hline 5 & A & Kosong & B & Terisi & c & Kosong & d & Kosong \\
\hline 6 & A & Kosong & B & Terisi & c & Kosong & D & Terisi \\
\hline 7 & A & Kosong & B & Terisi & C & Terisi & d & Kosong \\
\hline 8 & A & Kosong & B & Terisi & C & Terisi & D & Terisi \\
\hline 9 & A & Terisi & b & Kosong & c & Kosong & d & Kosong \\
\hline 10 & A & Terisi & b & Kosong & c & Kosong & D & Terisi \\
\hline 11 & A & Terisi & b & Kosong & C & Terisi & d & Kosong \\
\hline 12 & A & Terisi & b & Kosong & C & Terisi & D & Terisi \\
\hline 13 & A & Terisi & B & Terisi & c & Kosong & d & Kosong \\
\hline 14 & A & Terisi & B & Terisi & c & Kosong & D & Terisi \\
\hline 15 & A & Terisi & B & Terisi & C & Terisi & d & Kosong \\
\hline
\end{tabular}

\subsection{Pengujian Software}

Tampilan VB diuji dengan bantuan dari Arduino Uno dan sensor LDR, yaitu dengan cara menguhubungkan board arduino uno dengan PC melalui komunikasi USB. Menu yang terdapat pada form VB akan difungsikan dengan cara menghubungkannya dengan 
board arduino untuk melihat apakah form VB dapat terhubung dan menampilkan data dari arduino uno. Warna merah pada form VB menandakan bahwa slot parkir telah terisi, sedangkan warna hijau menandakan slot parkir masih tersedia

\section{PENUTUP}

Setelah melakukan perancangan dan pengujian pada sistem monitoring area parkir mobil, dapat ditarik beberapa kesimpulan sebagai berikut :

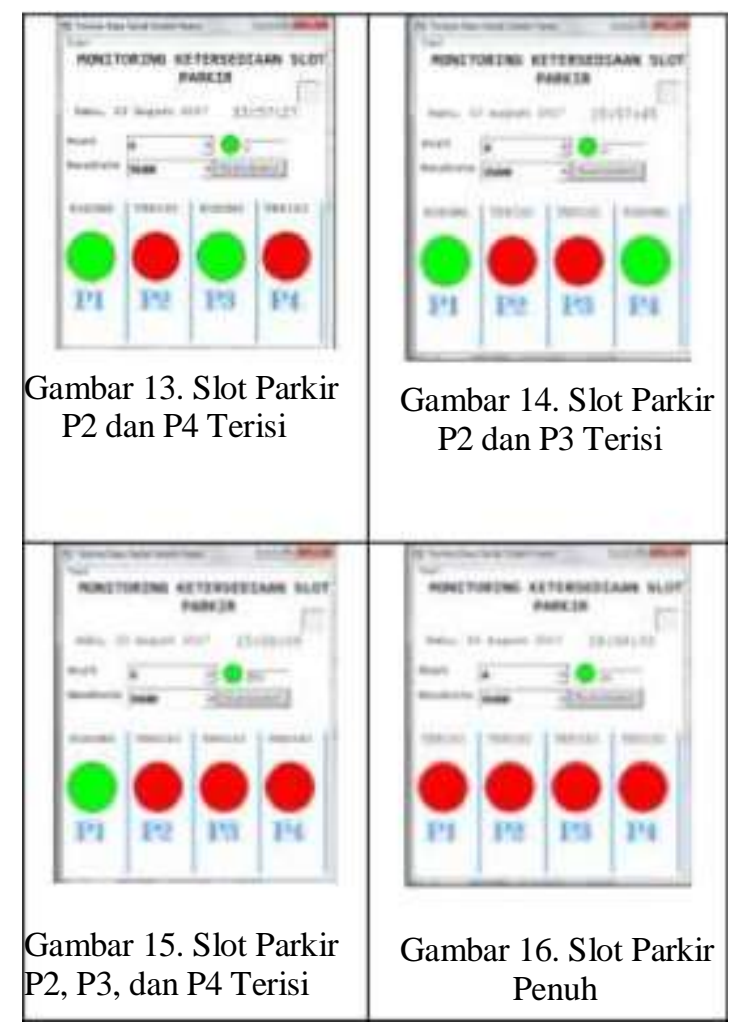

1. Telah dibuat purwarupa sistem monitoring yang digunakan sebagai pemantau dari area parkir mobil. Purwarupa sistem parkir ini dirancang dengan menggunakan Arduino
Uno sebagai otaknya yang akan memproses data masukan dari tiap sensor di slot parkir dengan menggunakan sensor LDR sebagai detektor keberadaan mobil pada slot parkir.

2. Purwarupa ini memiliki empat buah slot parkir dan dua buah palang pintu, yaitu palang pintu masuk dan palang pintu keluar dengan jarak yang berbeda. Buzzer pada palang pintu masuk pada sistem ini akan berbunyi apabila ada mobil yang akan masuk ketika semua slot parkir telah terisi.

3. Aplikasi monitoring area parkir ini berfungsi sebagai penerima dan memproses data sekaligus sebagai tampilan yang disimpan pada pintu masuk yang dapat menampilkan informasi berupa jumlah slot parkir dan dimana lokasi slot parkir kosong yang tersedia.

4. Cara pengkoneksian antara Mikrokontroler, Visual Basic serta keseluruhan parkir serta penempatan sensor pada setiap pintu masuk dan keluar area parkir dapat berfungsi dengan baik.

\section{DAFTAR PUSTAKA}

[1]. Djuandi, Feri, Pengenalan Arduino, Elexmedia, Jakarta, 2011

[2]. E-book Panduan Praktis Arduino untuk Pemula Hari Santoso V.1

[3]. Wahana Komputer Semarang dan penerbit Andi yogyakarta, Pemograman Visual Basic 